\title{
TITLE:
}

\section{$<$ Note $>$ Fission-Fusion in Chimpanzees: Feeding as a Proximal Mechanism at Gombe}

\section{$\operatorname{AUTHOR}(S)$ :}

Blackburn, Andrea; McGrew, William C.

\section{CITATION:}

Blackburn, Andrea ... [et al]. <Note> Fission-Fusion in Chimpanzees: Feeding as a Proximal Mechanism at Gombe. Pan Africa News 2013, 20(2): 19-22

ISSUE DATE:

2013-12

URL:

http://hdl.handle.net/2433/180552

\section{RIGHT:}

Copyright (C) Pan Africa News. 
quickly detect population changes. Also, further studies must emphasize more detailed data on tree phenology that chimpanzees rely on. As Nyungwe and Kibira National Parks are contiguous, an effective transboundary strategic plan to conserve both parks as one landscape is necessary to maintain viable population of chimpanzees.

\section{ACKNOWLEDGMENTS}

Financial support for this work came from Burundian Government, with additional funds being provided by Patrimoine de l'Université de Liège, International Foundation for Science (IFS) and Ecole régionale post-universitaire d'aménagement et de gestion intégrée des forêts tropicales (ERAIFT) via WBI program. Thanks are due to the guards of KNP, without whom this work could not have been carried out. We thank Nicolas Granier, Charles-Albert Petre, and Philippe Tamini for their helpful cooperation. We are grateful to Dr. Sandra Tranquilli for her helpful comments on the manuscript.

\section{REFERENCES}

Arbonier M 1996. Parc National de la KIBIRA: Plan de Gestion. INECN/CIRAD-FORET.

Balcomb SR, Chapman CA, Wrangham RW 2000. Relationship between chimpanzee (Pan troglodytes) density and large, fleshy-fruit tree density: conservation implications. Am J Primatol 51:197-203.

Baldwin PJ, McGrew WC, Tutin CEG 1982. Wide-ranging chimpanzees at Mt. Assirik, Senegal. Int J Primatol 3:367-385.

Barakabuye N, Mulindahabi F, Plumptre AJ, Kaplin K, Munanura I, Ndagijimana D, Ndayiziga O 2007. Conservation of Chimpanzees in the Congo Nile Divide forests of Rwanda and Burundi: Unpublished Report. No 98210-G-GO95/GA 0282. Arlington VA: US Fish and Wildlife Service (USFWS).

Buckland ST, Anderson DR, Burnham KP, Laake JL, Borchers DL, Thomas L 2001. Introduction to Distance Sampling: Estimating Abundance of Biological Populations. Oxford University Press, Oxford.

Buckland ST, Plumptre AJ, Thomas L, Rexstad EA 2010. Design and analysis of line transect surveys for primates. Int J Primatol 31:833-847.

Caldecott J, Miles L 2009. Atlas Mondial des Grands Singes et de leur Conservation. UNESCO, Paris.

Johns AD, Skorupa JE 1987. Responses of rain-forest primates to habitat disturbance: review. Int J Primatol 8:157-191.

Keele BF, Heuverswyn FV, Li Y, Bailes E, Takehisa J, Santiago ML, Bibollet-Ruche F, Chen Y, Wain LV, Liegeois F, Loul S, Ngole EM, Bienvenue Y, Delaporte E, Brookfield JFY, Sharp PM, Shaw GM, Peeters M, Hahn BH 2006. Chimpanzee reservoirs of pandemic and nonpandemic HIV-1. Science 313:523-526.

Kouakou CY, Boesch C, Kuehl H 2009. Estimating chimpanzee population size with nest counts: validating methods in Taï National Park. Am J Primatol 71:447-457.

Kühl H, Maisels F, Ancrenaz M, Williamson EA 2009. Lignes Directrices pour de Meilleures Pratiques en Matière d'Inventaire et de suivi des Populations de Grands Singes. Gland, Suisse : Groupe de spécialistes des primates de la CSE de l'UICN. 32 pp.

Morgan D, Sanz C, Onononga J R, Strindberg S 2006. Ape abundance and habitat use in the Goualougo Triangle, Republic of Congo. Int J Primatol 27:147-179.

Oates JE 1996. African Primates: Status Survey and
Conservation Action Plan, Revised Edition. IUCN/SSC.

Plumptre AJ, Reynolds V 1996. Censusing chimpanzees in the Budongo forest, Uganda. Int J Primatol 17:85-99.

Plumptre AJ, Rose R, Nangendo G, Williamson EA, Didier K, Hart J, Mulindahabi F, Hicks C, Griffin B, Ogawa H, Nixon S, Pintea L, Vosper A, McClennan M, Amsini F, McNeilage A, Makana JR, Kanamori M, Hernandez A, Piel A, Stewart F, Moore J, Zamma K, Nakamura M, Kamenya S, Idani G, Sakamaki T, Yoshikawa M, Greer D, Tranquilli S, Beyers R, Furuichi T, Hashimoto C, Bennett E 2011. Chimpanzé de Schweinfurth (Pan troglodytes schweinfurthii) : État de Conservation de l'Espèce et Plan d'Action 2010-2020. Groupe de spécialistes des primates de la CSE/UICN, Gland, Suisse.

Thomas L, Laake JL, Rexstad E, Strindberg S, Marques FFC, Buckland ST, Borchers DL, Anderson DR, Burnham KP, Burt ML, Hedley SL, Pollard JH, Bishop JRB, Marques TA 2009. Distance 6.0. Release 2. Research Unit for Wildlife Population Assessment, University of St. Andrews, UK. http://www.ruwpa.st-and.ac.uk/distance/

Tweheyo M, Lye KA, Weladji RB 2004. Chimpanzee diet and habitat selection in the Budongo Forest Reserve, Uganda. Forest Ecol Manag 188:267-278.

\section{<NOTE>}

\section{Fission-Fusion in Chimpanzees: Feeding as a Proximal Mechanism at Gombe}

\author{
Andrea Blackburn \& William C. \\ McGrew \\ Department of Archaeology \& Anthropology, University of \\ Cambridge, U.K \\ (E-mail:wcm21@cam.ac.uk)
}

\section{INTRODUCTION}

Fission-fusion is the species-typical and universal social organisation of Pan troglodytes, as recognised 45 years ago by the pioneering field research of such researchers as Goodall (1968), Nishida (1968) and Sugiyama (1968). In fission-fusion, the group (or community), subdivides into temporary parties, which may further fragment or reunite, such that over the course of a day, an individual may be solitary or sociable to varying degrees (Aureli et al. 2008). The standard variable for measuring fission-fusion is party size, that is, the number of individuals in spatial association in any one period or point in time. Explanations for variation in party size are many, but the most prevalent one is feeding competition, so that the larger the party, the greater the competition. Thus, individuals seeking to reduce or avoid competition will fission, either to forage alone or with fewer companions. Following this line of argument, we hypothesise that party sizes will be lower during bouts of feeding than before or after feeding.

\section{BACKGROUND}

Wrangham (1977) was the first to posit a positive correlation between group size and feeding competition in 
chimpanzees. (In the broad sense, 'group' indicates any aggregation, in any species, primate or otherwise.) The logic is simple: If resources are finite at any point in space and time, then the more organisms seeking to harvest those resources at the same time and place, the greater will be the competition, all other things being equal. For chimpanzees, the group size problem is 'subcontracted' to ephemeral parties, yielding maximum flexibility in dayto-day social relations. At one extreme is solitary foraging, when resources are sparse, versus maximally social foraging, in which party size is $100 \%$ of group size, when resources are abundant. Many other variables also influence group size, such as predation, reproduction, aggression, rank, seasonality, demography, etc. (see Aureli et al. 2008, for the most comprehensive and ambitious attempt to model fission-fusion).

For chimpanzees, many studies have found correlations between party size and proxy measures of feeding competition (e.g. Matsumoto-Oda et al. 1998; NewtonFisher et al. 2000; Itoh \& Nishida 2007). The usual study design is to relate party size (however defined) to one or more measures of food supply, such as fruit availability, in terms of abundance or distribution of resources. These measures of food supply are then related to various other measures, such as number of oestrous females, wet versus dry season, etc. Most (but not all, see Hashimoto et al. 2003) studies have found the expected relationship: When resources are scarce, chimpanzees range in smaller parties than when resources are abundant.
However, gaps exist in these studies. Party size (however defined) is a static ('snapshot') measure, sampled at various points in time over the course of a day. We have found no studies based on focal sampling that describe the dynamics of the process, for example, tell us how many fission-fusion transitions a chimpanzee makes in a day. Or what factors (activity, age, sex, rank, etc.) prompt a chimpanzee to leave or join a party. Furthermore, although the hypothesised causal variable is feeding competition, we can find no published data that directly address this, either by contest or scramble. Most studies do not measure feeding but instead rely on food, usually in terms of availability (versus, e.g., quality). Many studies of food supply do not relate it to actual chimpanzee foraging, much less to competition (e.g. Isabirye-Basuta, 1988). Thus, descriptive studies at this macro-level are indirect and correlative only (see Kummer 2008, Yamagiwa 2008, for similar comments on the lack of ethological data).

We sought to tackle some of these issues at the sequential, dynamic, micro-analytical level, by comparing party sizes when feeding versus non-feeding, in real-time sequences, focussing on individual behaviour. Other studies have shown static differences in group size in relation to activity (e.g. Newton-Fisher, 1999), but none seems to have made this basic comparison.) We chose to test the hypothesis in the most sociable age-sex class of chimpanzees, independently-ranging males, because it is the most challenging one.

Table 1. Number of companions of independently-ranging male chimpanzees at Gombe, before, during and after bouts of feeding. See text for explanation of four stages.

\begin{tabular}{|c|c|c|c|c|c|c|c|c|}
\hline \multirow[b]{3}{*}{ Subject } & \multicolumn{8}{|c|}{ Number of companions } \\
\hline & \multicolumn{2}{|c|}{$30 \mathrm{~min}$ before } & \multicolumn{2}{|c|}{ Start feeding } & \multicolumn{2}{|c|}{ Stop feeding } & \multicolumn{2}{|c|}{30 min after } \\
\hline & $n$ & median & $n$ & median & $n$ & median & $n$ & median \\
\hline $\mathrm{EV}$ & 9 & 3 & 84 & 2 & 84 & 2 & 7 & 6 \\
\hline FB & 15 & 7 & 68 & 4.5 & 68 & 5.5 & 17 & 7 \\
\hline $\mathrm{FG}$ & 4 & 2 & 48 & 2.5 & 48 & 3 & 3 & 2 \\
\hline GB & 5 & 2 & 62 & 2 & 62 & 2 & 6 & 2.5 \\
\hline $\mathrm{HG}$ & 5 & 2 & 44 & 2 & 44 & 3 & 4 & 7 \\
\hline HM & 7 & 4 & 53 & 2 & 53 & 2 & 7 & 3 \\
\hline $\mathrm{JJ}$ & 7 & 4 & 57 & 2 & 57 & 2 & 5 & 7 \\
\hline $\mathrm{MK}$ & 8 & 7 & 46 & 1 & 46 & 1.5 & 7 & 4 \\
\hline $\mathrm{SH}$ & 4 & 6.5 & 46 & 0 & 46 & 0 & 7 & 7 \\
\hline $\mathrm{ST}$ & 5 & 2 & 50 & 1 & 50 & 1 & 6 & 1.5 \\
\hline Total & 69 & - & 558 & - & 558 & - & 69 & - \\
\hline Median & 6 & - & 51.5 & - & 51.5 & - & 6.5 & - \\
\hline $\begin{array}{l}\text { Median of } \\
\text { medians }\end{array}$ & & 3.5 & & 2 & & 2 & & 5 \\
\hline
\end{tabular}




\section{METHODS}

We used archival data from Travel \& Group charts (T\&Gs) recorded throughout the year 1973 at the Gombe Stream Research Centre, mostly by Caroline Tutin (COPS study) and McGrew (KIDS and TERM studies). T\&Gs were records of focal-subject samples of independently moving chimpanzee subjects, followed by a researcher and field assistant for variable periods, up to a whole active day (i.e. nest-to-nest). For details and results from this data instrument, see Goodall 1986.

For this analysis, we focussed on the T\&G column labelled FOOD, in which duration of bouts of feeding (to the nearest 5-min) and species fed-upon by the focal subject were the only data available. Feeding was defined as items being inserted into the mouth but not expelled, i.e. were ingested. A feeding bout was defined as a continuous session of feeding on one prey item by the subject, from start to finish.

We also used data from 10 of the 19 T\&G columns labelled by the two-letter initials of adult and subadult males (EV, FB, FG, GB, HG, HM, JJ, MK, SH, ST), all members of the Kasekela community see Table 1). The other 9 males, mostly from the less-studied Kahama community, had too few records. A focal subject could have up to 41 companions in a party; younger individuals, typically offspring, were not included, as they did not move independently. These data yielded number of companions with the focal subject in 5-min, one-zero frequency units. Number of companions was preferred as the dependent variable based on semantics (i.e. party is a plural term, so a party-size of one is nonsensical) and computation (i.e. allows for a party size of zero to be a lone individual).

Finally, we noted the column labelled IN CA, which distinguished In Camp versus Out of Camp records. (Camp denoted the feeding area, where provisioning with bananas was done.) The 50 In Camp records found were excluded from further analyses, as being unnatural.

The following data were extracted: Number of companions at the beginning and end of each Out of Camp feeding bout $(n=558)$, plus party size $30 \mathrm{~min}$ before and 30 min after the feeding bout $(n=69)$. Thirty min was arbitrarily chosen, based on comparing behaviour 'beforeduring-after' feeding, in earlier studies of chimpanzee behaviour (e.g. de Waal 1987). Thus data were collected at four sequential points in time. However, we excluded all cases in which the 'before' or 'after' data were compromised by another feeding bout during the intervening 30 min interval, which greatly reduced the number of fourpoint sequences.

Data were entered into a Microsoft Access 2013 database (spreadsheet). Statistical testing was non-parametric, as the conditions for parametric testing could not be met (Siegel \& Castellan 1988). Accordingly, we used medians rather than means, and alpha was set at 0.05 , one-tailed.

\section{RESULTS}

Number of companions varied across the four conditions (stages): Friedman two-way analysis of variance, $n$ $=10, k=4, \chi^{2}=70.8, p<0.001$ (see Table 1, Figure 1). Pair-wise comparisons between conditions also varied in three of four cases: Number of companions decreased in

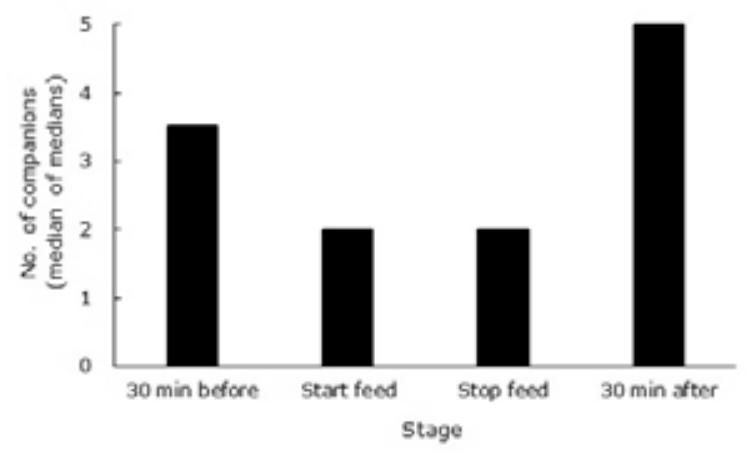

Figure 1. Number of companions (median of medians) for 10 independently-ranging male chimpanzees at Gombe, before, during and after bouts of feeding.

number from $30 \mathrm{~min}$ before the start of the next feeding bout (Binomial test, $n=8$, excluding ties, $p=0.035$ ) and increased in number $30 \mathrm{~min}$ after the end of the last feeding $(n=5, p=0.01)$. Despite having equal medians, number of companions increased from the start to the end of feeding bouts $(n=10, p=0.03)$. There was no difference in number of companions between $30 \mathrm{~min}$ before versus 30 min after feeding bouts $(n=8, p>0.05)$.

Thus, males fed with fewer companions than they had a half hour before the next bout of feeding, and a half hour after finishing feeding they had more companions. Moreover, in a typical feeding bout, a male had more companions at the end of it than he had at the beginning. Number of companions (effectively party size, as above) before and after feeding did not differ in number.

\section{DISCUSSION}

The hypothesis was upheld. Gombe's adult male chimpanzees somehow manage their fission-fusioning, so that they were in smaller parties when feeding versus when not feeding. Thus, sequential, individual data at the more specific, proximate level agree with correlational data at the more general, ultimate level. The apes may achieve this by avoiding others before starting to feed, only then to seek others after feeding. However, this dataset yields no details on how the increases and decreases in number of companions are managed. Explanation awaits further detailed ethological study.

We made no prediction about whether party size would increase or decrease during an individual's feeding bout, as either alternative is a reasonable expectation. A male might recruit others (e.g. Clark \& Wrangham 1993) and so increase party size, or party sizes might shrink as the patch's food is depleted. Or, party size might remain constant over a feeding bout, as on average, differing tendencies counter-balance. In any case, Gombe's males had slightly more companions at the end of a feeding bout than at its outset. This could indicate recruitment or just random but cumulative discovery of the food source by others. Again, to explain this finding requires more focussed, specific data than are available here.

\section{ACKNOWLEDGEMENTS}

We thank: Gombe colleagues, and especially Caroline 
Tutin, for retrospective use of their data; Miami University Honors Program and Linda Marchant for funding for AB; The Leverhulme Trust for funding for WM; Noriko Itoh for comments on the manuscript.

\section{REFERENCES}

Aureli F, Schaffner CM, Boesch C, Bearder SK, Call J, Chapman CA, Connor R, Di Fiore A, Dunbar RIM, Henzi SP, Holekamp K, Korstjens AH, Layton R, Lee P, Lehmann J, Manson JH, Ramos Fernandez G, Strier KB, van Schaik CP 2008. Fission-fusion dynamics: new research frameworks. Cur Anthropol 49:627-654.

Clark AP, Wrangham RW 1993. Acoustic analysis of wild chimpanzee pant hoots: do Kibale Forest chimpanzees have an acoustically different food arrival pant hoot? Am J Primatol 31:99-109.

Goodall JvL 1968. The behaviour of free-living chimpanzees in the Gombe Stream Reserve. Anim Behav Monog 1:161-311.

Goodall J 1986. The Chimpanzees of Gombe. Harvard University Press, Oxford.

Hashimoto C, Suzuki S, Takenoshita Y, Yamagiwa J, Basebose AK, Furuichi T 2003. How fruit abundance affects the chimpanzee party size: a comparison between four study sites. Primates 44:77-81.

Isabirye-Basuta G 1988. Food competition among individuals in a fre-ranging chimpanzee community in Kibale Forest, Uganda. Behaviour 105:135-147.

Itoh N, Nishida T 2007. Chimpanzee grouping patterns and food availability in Mahale Mountains National Park, Tanzania. Primates 48:87-96.

Kummer H 2008. Comment on Aurelli et al.. Cur Anthropol 49:644-645.

Matsumoto-Oda A, Hosaka K, Huffman MA, Kawanaka K 1998. Factors affecting party size in chimpanzees of the Mahale Mountains. Int J Primatol 19:999-1011.

Newton-Fisher NE 1999. Association by male chimpanzees: a social tactic? Behaviour 136:705-730.

Newton-Fisher NE, Reynolds V, Plumptre A 2000. Food supply and chimpanzee (Pan troglodytes schweinfurthii) party size in the Budongo Forest Reserve, Uganda. Int J Primatol 21:613-628.

Nishida T 1968. The social group of wild chimpanzees in the Mahali Mountains. Primates 9:167-224.

Siegel S, Castellan, NJ 1988. Nonparametric Statistics for the Behavioral Sciences. McGraw-Hill, New York.

Sugiyama Y 1968. Social organization of chimpanzees in the Budongo Forest, Uganda. Primates 9:225-258.

de Waal FBM 1987. Tension regulation and nonreproductive functions of sex in captive bonobos (Pan paniscus). Natl Geog Res 3:318-335.

Wrangham RW 1977. Feeding behaviour of chimpanzees in Gombe National Park. In: Primate Ecology. Clutton-Brock TH (ed), Academic Press, London, pp. 504-538.

Yamagiwa J 2008. Comment on Aurelli et al.. Cur Anthropol 49:645-646.

\section{<NOTE>}

\section{A Juvenile Chimpanzee Played with a Live Moth}

\author{
Michio Nakamura \\ Wildlife Research Center, Kyoto University, Japan \\ (E-mail:nakamura@wrc.kyoto-u.ac.jp)
}

\section{INTRODUCTION}

Although it is not common for chimpanzees (Pan troglodytes) to capture and toy with small mammals or birds without eating them, several reports have indicated that this does sometimes occur (e.g., Hirata et al. 2001; Zamma 2002; Carvalho et al. 2010). These reports compared such incidents with chimpanzees' hunting behaviors because it seems puzzling that the chimpanzees did not eat the meat. However, it is possible that a chimpanzee may show an interest in a living organism for its animacy per se, with no intention of eating it.

This paper reports the case of a juvenile female chimpanzee at Mahale that captured and played with a live moth (Lepidoptera). Although chimpanzees frequently prey on several insect species (mostly social insects) (e.g., McGrew 1992; Fuse 2013), Mahale chimpanzees eat moths only rarely (Nishida \& Uehara 1983).

\section{OBSERVATION}

The observation focused on chimpanzees in the M group at the Mahale Mountains National Park (see Nishida 2012 for details of the study site). At 09:19 a.m. on 12 October 2004, two adult female chimpanzees and their offspring had been taking a rest under a dense bush since 08:54 a.m. when Ichiro (IH: a 1-year-old male) emitted a slight huu call and was observed to be watching something on the ground. When IH touched the object with his finger, it moved, and I could then see that it was a large moth, about $5-6 \mathrm{~cm}$ in size and beige in color. Its body was thick, and its forewings were much longer than its hindwings. IH's mother, Ikocha (IK), immediately approached him, put him on her belly, moved away, and sat about $1 \mathrm{~m}$ away from the moth. Soon, IH's older sister, Imani (IM: a 6-year-old female), went to where the moth lay and started to investigate it. Because my initial view was largely obstructed by dense bush, I moved to the side to gain a better view and started to take a video.

IM captured the moth without killing it and started to play with it, sometimes vigorously, sometimes calmly. Given her occasional play face and play pant, IM's series of behaviors was regarded as playful. I summarize the behavioral patterns observed during IM's play in Table 1 (see Video 1: available online at mahale.main.jp/ PAN/20 2/20(2) $03 . h t m l)$. The moth sometimes fluttered its wings while being pinched between IM's fingers or lips. Although IM frequently put the moth in her lips or touched it with her lip, she did not try to eat it.

While IM was playing with the moth, IH approached her twice, and she responded playfully to him. At 09:25, IM put the moth in her groin pocket and slowly walked away into the bush; at 09:26, I lost sight of her because I could go no further into the bush. When she was observed 